CASE REPORT

AFRICAN JOURNAL OF CLINICAL AND EXPERIMENTAL MICROBIOLOGY AJCEM/201108/21127

COPYRIGHT 2011

AFR. J. CLN. EXPER. MICROBIOL 12(3): 133-135
SEPTEMBER 2011 ISBN 1595-689X VOL 12(3)

-http://www.ajol.info/journals/ajcem

doi: 10.4314/ajcem.v12i3.9

\title{
DEMODECOSIS IN A DOG
}

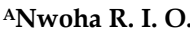

ADEPARTMENT OF VETERINARY MEDICINE, AMICHEAL OKPARA UNIVERSITY OF AGRICULTURE, UMUDIKE. P.O.BOX 824, UMUAHIA, NIGERIA. E.MAIL rosemarynwoha@yahoo.com phone 08030987115.

\begin{abstract}
\section{INTRODUCTION}

Amongst all the species of animals, dogs are the closest to man because of their sophisticated social behaviors (1). The different breeds serve various purposes to man ranging from draught dogs for work, guard dogs for protection, assistant dogs to aid the blind and physically challenged, detective dogs to aid in criminal investigations and most importantly pet dogs for mans' companion (2). Most pet owners have a close relationship with their dogs and often spend their leisure time cuddling them.
\end{abstract}

Dogs are the most common pet animals worldwide. They sometimes harbour a wide range of parasitic diseases with zoonotic potentials, predisposing humans to health risk. Demodecosis is a parasitic disease that is often seen in young dogs of less than a year, immunodeficient adults and old dogs. Generalized demodecosis when it occurs in a dog may take months and years to treat. Infected animal has persistent puritis due to intense itching from Demodex canis. Such animal often inflicts wounds on the body due to persistent scratching and therefore should not under go aesthetic surgery until demodecosis is completely treated. The constant scratching of the body by the dog could traumatize the surgical site perphaps leading to evisceration and death of the animal if not promptly handled.

Keywords: Dog, evisceration, generalized demodecosis, aesthetic surgery.

These pets are sometimes faced with various forms of skin diseases such as "mange" infection which often isolate them from man. Mange otherwise known as ascariasis is a persistent contagious skin disease of animals and man caused by parasitic mites (3). The disease is common among canine species and manifests in three different forms $(4,5$, $6)$. Cheyletiella mange is the least pathogenic. It manifest as dandruff and slight itching (5). Sarcoptic mange also known as canine scabies is more serious, highly contagious and zoonotic (6). Canine scabies can infect all species of animals including man (3). Clinical signs manifests in form of intense itch, injury to the skin, weeping skin lesions, crusts and scab formations often seen at the elbow and ear region $(5,7)$.

Demodectic mange, also known as demodecosis or Red mange, is the third form and the most serious type caused by demodex canis $(4,8,9)$. Demodecosis is non contagious and can only be seen in immunodeficient animals, old dogs and young puppies of about 3 months to a year infected in utero $(4,7,10-13)$. Demodex canis burrow deep into the skin feeds and secrete substance that reduces the innate resistance of infected dogs (vii). The disease is thought to be hereditary often seen in oily skinned, short haired, pubescent dogs and rare in puppies raised by hand and young adults $(10,11)$. Both sexes have the same ability to transmit genetic predisposition to demodecosis (9). However, (8) reported a higher prevalence of disease in long haired dogs. Dogs with localized form of demodecosis develop alopecic areas around the eyelids, lips, mouth and front limb giving the animal a characteristic moth-eaten appearance (7). Infected puppies recover by their fourteenth month as their immunity develops (15). Otherwise, the disease becomes chronic and generalized showing large alopecic areas on various parts of the body which coalesce into large bald areas (6). The hair follicles maybe plugged with debris and demodex canis mites with draining sinus tracts giving the animal a strong foal odour $(4,15,16)$. At this stage the animals may be at risk of secondary bacterial infection and complications of pododemodecosis affecting the paws $(7,8)$.

Diagnosis is by deep skin scrapping into $\mathrm{KOH}$ or $\mathrm{H}_{2} \mathrm{O}_{2}$ to digest the debris and release the mites (4). However, most times it's difficult to identify mites under the microscope and treatment is often commenced based on the obvious clinical signs (3). A common simple way of diagnosis is by "Pedalpinna reflex" technique where by the dog moves its hindlimb in scratching motion as the examiner gently manipulate and scratches the ear (3). This technique is effective for over $95 \%$ of most mange cases because these mites proliferate around the ear region at some point in time. Treatment is of a great controversy amongst Vets. Some recommends small daily shots of ivermectin along with medicated bath for 3-4 weeks (5). Others prefer weekly injection of ivermectin shots or orally $(3,7)$. However, some breeds of dogs especially the herding dogs such as Collies, Shetland sheep dog and old English sheep dogs are sensitive to ivermectin. Such dogs should be 133 
treated with medicated sampoo containing benzylperoxide as the active ingredient. The hair should be first clipped off for ease of penetration into the skin. They may also be treated with multiple insecticide dips containing lyme sulfur, paramite such as dermisil which have been approved by FDA or mitaban bath. Mitaban dip should be avoided in young puppies because of its sedative effect $(4,5,7)$. The use of hydrocodone in reliving the itching is also a bone of contention amongst vets. (15) disapproves its use perhaps because of its immunosuppressive effect which will have a negative effect in the recovery of the infected animal. (7) approves it use probably to relief the intense itching and scratching of the body. Newer methods of treatment include the use of interceptors, used in the treatment of heartworm. This method is rather expensive and tidous (7). FDA has recently approved the use of promeris a topical flea and tick medication for treatment of demodecosis (6). Some anecdotal reports claims the use of a mixture of two liters of seawater (salt water) in a half cut calabash and three fresh limes coated all over the affected areas and allowed for the day before rinsing cure mange. The procedure is to be repeated two to three times after which the animal recovers.

\section{CASE REPORT}

A six months old local breed of dog, weighing $8 \mathrm{~kg}$ was presented on 12 th September 2010 for castration at the college of veterinary medicine Michael okpara

university of university umudike. Physically examination of the dog shows a case of generalized mange. The lesions were seen on the forelimb, under the neck, the dorsum, ventral abdomen, head and the lateral aspect of the shoulder just below the neck region. The lesions are somewhat circumscribed and spreading with reddish center and necrotic scabs at the periphery. The lesions under the neck region became clearer when the head was raised up. The temperature was 38.7oc, heart rate $120 / \mathrm{min}$, pulse rate $110 / \mathrm{min}$. Skin scrapings were collected into a container with $\mathrm{KOH}$. The sample was analyzed and demodex canis confirmed at the department of veterinary

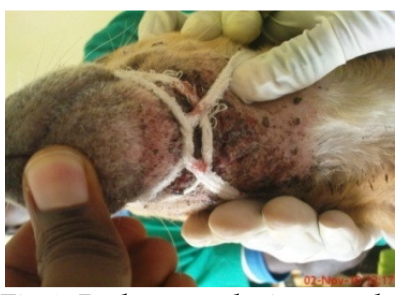

Fig 1: Red mange lesions under the neck region of a dog

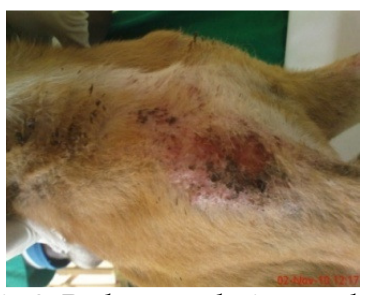

Fig 2: Red mange lesion on the upper fore limb of the dog. parasitology through method described by (xvii). After clinical investigations were completed, the animal was castrated and sutured with unabsorbable catguz wire. The patient was given procaine penicillin injection at the dose of $10,000 / \mathrm{iu}$ and was discharged. The treatment for demodecosis commenced two days later. The animal was placed on weekly shots of ivermectin. A week later, the client brought the dog for treatment and it was discovered that the dog has loosen its stitches and there was accumulation of blood inside the wound. The wound was re sutured and treated along with ivermectin shot. Two weeks later, the client reported that he found the dog dead with some of its viscera outside.

\section{DISCUSSION/ CONCLUSION/ RECOMMENDATION}

According to the case report, the demodecosis was observed in a 6 months old local breed of dog. This agrees with $(4,6,10-13)$ who said that demodecosis is mainly seen in dogs of about 3 months to one year of age. This could be as a result of the fact that dogs within the age bracket still have juvenile immune system which is unable to produce specific and sufficient antibodies to clear the demodex canis mites $(6,14$, and 18). The generalized demodecosis is in line with the findings of (6) that demodecosis could be localized or generalized as the case may be. The spreading and dissemination of the disease only confirms the inability of the immune system to checkmates and clear the infection (6). The described lesions on the body as circumscribed spreading with reddish center and necrotic periphery agrees with (4). He described the lesions as reddish hence the name red mange. The reddish lesions are thought to be due to intense itching from the mites and constant scratching of the affected areas by the dog and continuously inflicting fresh wounds on the areas. The temperature of $38.9 \mathrm{oc}$, Heart rate of $120 / \mathrm{min}$ and pulse rate of $110 / \mathrm{min}$ were all normal for the dog. Other workers on mange recorded similar observations. This could mean that mange is simply a skin disease with no systemic effect except perhaps in secondary bacteria infection (4). 
The skin scrapping used in the diagnosis of the case conforms to $(3,17)$ stating that skin scrapings are made into container of $10 \% \mathrm{KOH}$. The $10 \% \mathrm{KOH}$ is for the digestion of the scabs and necrotic tissues,

releasing the mites. The centrifuged medium at $3000 \mathrm{rev}$ for 10mins was decanted and the supernatant viewed under the microscope for the presence of demodex canis mite (19). However, identification of mites through this method is a little difficult $(3,6)$. The pedal reflex technique has about 95\% accuracy easy to carry out but will not tell the particular specie involved.

Most importantly, the dog after being confirmed to have generalized demodecosis shouldn't have been castrated. This is because demodex canis burrow deep into the skin causing intense itching to the dog $(5,6)$. The infected dog will constantly be scratching the body inflicting wounds on the body which are liable to bacterial infection (4). Also, while scratching the dog will constantly loosen the stitches and may cause trauma to tissues and if not promptly attended to may lead to evisceration and

\section{REFERENCES}

1. Ugbomoiko, U. S.; Ariza,.L. and Heukelbach, J. Parasites of importance for human health in Nigerian dogs: high prevalence and limited knowledge of pet owners.Vet Res. 2008; 4: 49.

2. Association of veterinary medical student (AVMS) 2004. Dogs As Man Companion. Brigestome 2004; 1-5.

3. Wikipedia. Mange. Wikimedia Foundation Inc. 2010.

4. Kaminsky, A. What is the Best Treatment for Mange? wiseGEEK.com. 2010.

5. Mange In Dogs. A Complete Guide To Dog Mange. Mange-In-Dogs.Com. 2010.

6. Ardeth .B. Treatment of Mange, An explanation of the various types of mange in dogs and cats-all caused by mites--their degree of seriousness, treatment, and prevention. Demandmedia Network. 2002

7. Nayak, D. C; Tripathy, S. B; Dey, P. C; Ray, D. N Mohanty, G. S; Parida, S; Biswal and Das, M. Prevalence of canine demodicosis in Orissa (India). J. Vet. Parasitol. 1997; 73: 347-352.

8. Marsalla R. Demodicosis (Red Mange) in Dogs .Petplace.com. 2010.

9. Morris, M. L. Demodex folliculorum canis. Its diagnosis and treatment. J. Am.Vet. Med. Assoc. 1936; 88: 460-467. death of the dog. Secondly, in a normal dog that was castrated; the stitches should be removed by the $7^{\text {th }}$ day post- castration because the wound will be fairly healed by then. Failure of the wound to heal by the $2^{\text {nd }}$ week could mean a possible immunosuppressive effect of the mite on the host. This agrees with $(6,7)$ that demodex canis secretes a substance that reduces the innate immunity of infected animal.

Conclusion/ Recommendation: Dogs with generalized demodecosis should not undergo aesthetic surgeries such as castration, tail docking and ear cropping until the animal recovers. Dog owner should present their pet for routine check up and prophylactic shots of ivermectin at monthly intervals. Treatment of demodecosis should commence immediately on diagnosis and should not stop until two or three negative skin scrapping results are made. Infected animals should be given immune boosters such as vitamin B complex for quick recovery and administration of omega-3 fatty acid supplement for skin restoration.

10. Koutz, F.R. Demodex folliculorum (iii) Asurvey of clinical cases iin dogs. J. Am. Vet. Med. Assoc. 1954; 123: 131-133.

11. Gaafar, S. M; Smalley, H. E; Turk, R.D. The incidence of demodex species on skin of apparently normal dogs. J.Am. Vet. Med. Asssoc. 1958; 133: 122-123.

12. Mishran, S.C; Sahoo, B; Patel, S. N. Studies on parasitic problems of puppies V. winter populations of helminths and arthropods on puppies at Bhubaneswar. Indian J. Anim. Res. 1974; 8: 89-91.

13. Dog health guide. dog health guide.com. 2010.

14. Smith, H.J. Bovine demodicosis. I incidence in Ontario Cnadan J. comp. Med. 1961; 25; 165-169.

15. Gortel, K. Update on canine demodecosis. Vet. Clin. Small Anim. Pract. 2006; 36: 229-241.

16. Nutting, W. B., Desch, C.E. Demodex canis. Redescription and revaluation. Cornell Vet. 1978; 68: 139-149.

17. Sarkar, P; Mkherjee, J; Ghosh, A; BhattSmith, H. J. Bovine demodecosis. I. Incidence in Ontario Canadian. J. Comp. Med. 1961; 25:165-169.

18. Baker, K.P. Observations on demodectic mange in dogs. J. Small Anim. Pract. 1968; 9: 621-625. 